\title{
The socio-cultural impacts of visiting friends and relatives on hosts: a Samoan study
}

\author{
R. G. Taufatofua ${ }^{1} \&$ S. Craig-Smith ${ }^{2}$ \\ ${ }^{1}$ Centre for Social Responsibility in Mining (CSRM), \\ Sustainable Minerals Institute, Australia \\ ${ }^{2}$ School of Tourism, University of Queensland, Australia
}

\begin{abstract}
This paper considers and compares the key impacts of the visiting friends and relatives (VFR) traveller and the holiday tourist on the socio-cultural fabric of Pacific Island community's. Research was undertaken in the islands of Samoa. A socio-cultural capital approach provided recognition of the dynamic natures of the communities considered. The VFR traveller is a particularly important yet largely under-estimated visitor segment in many Pacific islands where VFR travellers comprise a considerable percentage of visitors. Socio-cultural and economic impacts can be significant on host communities, particularly as the VFR traveller can slip beneath the cultural barrier separating the local resident from the tourist/traveller. The current research suggested that VFR travellers impact the socio-cultural fabric in similar ways to holiday tourists. However, host respondents accorded less concern to VFR traveller impacts than to holiday tourists. Impacts were largely considered positive, enhanced by the importance of this traveller segment through overseas remittances.

Elements impacted varied in strength of impact by traveller type. For example, reciprocity was considered impacted more so by VFR travellers, changing the nature of reciprocity from an intrinsic value to extrinsic value based on monetary exchanges. This research glimpses how the socio-cultural fabric operates particular resilience mechanisms to protect its integrity from undesirable external influences, yet embraces the more favourable influences. The research identifies that holiday and VFR tourism in Samoa does impact the socio-cultural fabric in a myriad of ways, some positive and others negative.
\end{abstract}

Keywords: socio-cultural resilience, social and cultural capital, visiting friends and relatives. 


\section{Introduction}

This report considers the impacts of the Visiting Friends and Relatives (VFR) travel market on four host communities in the Pacific Island nation of Samoa, The socio-cultural and economic impacts from tourism can be significant on host communities, often more pronounced in those countries where there are high levels of visitation. Tourism impacts have received widespread consideration; however, impacts have not been differentiated by traveller typologies. In particular VFR travellers have been largely overlooked with respect to impacts, planning and management strategies.

Research is criticized as failing to adequately explore socio-cultural and socio-demographic variables and behaviours of hosts and VFRs in host countries (Husbands [2], Young et al [3], McKercher [4]). Some studies even indicated that this relationship is not discernible (Belisle and Hoy [5], Liu et al [6], Lankford and Howard [7], Milman and Pizam [8], Ryan and Montgomery [9]). Jackson [10] filled some of the void studying resident characteristics and behaviours to understand the social and economic implications of entertaining VFR travellers. This consideration fell short of acknowledging that Pacific VFR travellers may contribute to socio-cultural change in respective communities.

This research specifically considered key impacts of the VFR traveller on the socio-cultural fabric of the Pacific Island communities in Samoa and where relevant compares them to impacts of the mainstream holiday tourist market.

\section{Methodology}

The VFR traveller was considered as part of a larger study which researched the impacts of tourism on local communities of Samoa. This research looked at two traveller types, holiday tourists and VFR travellers. Three distinctly different touristic locations were considered:

- Larger tourism operations in the capital of Apia;

- Medium Tourism operations. These consisted of family operations, beach fales / bungalows, in Lalomanu (Upolu) and in Manase (Savaii);

- Community with no tourism development in close proximity, the community of Aopo (Savaii) which acted as the control for the research. It was assumed at the onset of the research that a non-touristic area should show a different level of cultural change than touristic areas if tourism did affect cultural change and erosion.

Forty nine community members were interviewed individually and in focus group discussions. Perceived impacts (as identified by host residents) by holiday tourists and VFR travellers were identified and compared.

\subsection{A socio-cultural capital approach to the research}

A social and cultural capital approach was used to understand the complexity of communities, their networks and relationships in a dynamic and comprehensive way. This includes many dimensions of community norms, values and 
way. This includes many dimensions of community norms, values and behaviours, addressed to understand processes of change and what constitutes resilience to change in communities. This provided a means to measure multidimensional aspects of communities in contrast to singular dimensions of traditional measurement tools.

With the wide recognition that economic growth is not enough to attain quality of life, the importance of social and cultural capital in terms of connecting the past, present and future is highlighted (Mercer [11]). Put simply, a 'Social Capital' approach looks at the patterns and qualities of relationships within a community or society, and considers capacity to address and resolve issues and change, which they collectively experience (Saunders [12], Black and Hughes [13], ABS [14]). Cultural capital identifies individual's varying ability to learn and carry out culturally favoured behaviour and attitudes, differentiating their relative worth to a cultural group (Bourdieu [15]). Those with higher levels of cultural capital are more likely to dominate and influence a cultural group.

The elements of social and cultural capital explored in this research included: reciprocity; trust and trustworthiness; self efficacy; land ownership, family, shame, face and respect, the chiefly system, oratory, religion and spirituality, social cohesiveness, craftsmanship, building styles, tattoos, sense of belonging, sense of support, sense of inner peace and contentment; and values and beliefs. A combination of participatory action research techniques and critical ethnographic methodologies guided the research interaction with respondents. Analysis and interpretation of results used both quantitative and qualitative analytical methods. Significant cross-relationships between nominal and ordinal variables were analysed and strongly significant interrelationships investigated in line with multidisciplinary literature discussions.

\section{Discussion of research findings}

The study clearly identified that VFR travellers impacted several key elements of the socio-cultural fabric of those communities considered. The outcomes of the research showed similarities and differences between impacts of VFR travellers and holiday tourists. The critical aspects will be discussed in line with community resilience aligning discussion to the enhancement of sustainable community growth. The following aspects will be considered:

- VFR traveller typology to understand relevant characteristics

- Links between the Pacific VFR and a remittance culture

- Impacts on the socio-cultural capital of the communities.

- Links to socio-cultural resilience.

\subsection{Typology of travellers}

Tourism impacts can vary considerably by traveller type. What is clear from research and literature is that the VFR traveller segment is not a homogenous segment. Characteristics of these travellers may vary between countries, cultures and in response to other influences. 
Little research has been undertaken in the area of VFR travellers, let alone clear definitions of the typologies of the market segment, yet some researchers recognise the value of the VFR traveller market (Lehto et al [16], Moscardo et al [17] Lee et al [18], Duval [19]). This is in contrast to other authors who considered that the value of VFR travel is small compared with other forms of tourism (Seaton and Palmer [20]). Literature has largely addressed VFR travellers from a western context in UK, Canada, US, Australia and Europe. Recent studies in Australia considered the VFR definitional typology, essentially separating the traveller into two main groups, defined "by purpose" or "by accommodation" (Backer [21]). Yet this typology may have limited use in providing a comparative understanding of the Samoa VFR travel scenario, as 'purpose' is the predominant instigator of travel, 'accommodation' is generally secondary.

What can differentiate the Samoan VFR traveller from those from many other countries is that the social ties of the overseas Samoan remain strong and return visits remain an essential part of maintaining their Samoan identity (McGrath [22]). Many overseas Samoans consider themselves "Samoan first and foremost" and remain keenly interested in Samoan life and politics. Furthermore, most Samoan leaders have lived and studied overseas and hence been termed VFR travellers at some stage of their overseas lives. These people have introduced and guided Samoa in its integration of both fa'asamoa (Samoan) and fa'apalagi (Western) ways (UNESCO [23]).

The VFR traveller is a particularly important visitor segment in many small Pacific Islands where they comprise a considerable percentage of visitors. Indeed, in Samoa the VFR traveller segment makes up approximately 29 percent of total visitors, slightly behind the holiday sector (around 33 percent) (Central Bank of Samoa [1]). Despite recent declines in the market, earnings from VFR travellers (US\$7.7 million) are higher than holiday tourists (US\$5.7 million) (Central Bank of Samoa [1]). Central Bank assessments consider formal market earnings, whereas informal sector contributions (household goods, food and other assistance) have largely not been assessed and may provide a greater influence on households and the economy than formal sector earnings. This highlights the importance of this market segment and the need for socioeconomic planners to better understand the impacts and needs of this valuable segment in order to manage and sustain the segment more effectively.

\subsection{The Pacific VFR and links to a remittance culture}

Links between VFR travellers and out migration from the Pacific have been explored by several authors (Jackson [10], Springer [24], Duval [19]) directly linking migration and remittances to the VFR traveller. What is ironic is that although the Pacific Islands attract tourists who seek the Pacific paradise, many inhabitants of these paradise locations leave to seek employment and educational opportunities. Significant migration has occurred from some workforces, including approximately 50,000 Cook Islanders and 8,000 Niue Islanders. By 1993, one third of Samoans lived overseas, mainly in American Samoa, United States, Australia and New Zealand (Shankman [25]). 
A parallel remittance culture has developed. These VFR travellers remit money and goods while resident overseas to help provide for family needs (Samoan VFR traveller [26], NZ Ministry of Women Report [27]). Remittances have continued to rise over recent years to Samoa (an increase of 8 percent in 2005 worth approximately US \$248m), remaining a key source of family income a positive impact on the Samoan economy (Joint Samoa Program Strategy [28]). Many VFR travellers grew up with the same norms and values as hosts, yet have also adopted certain traits of their new homes. Upon migration people adopt characteristics of their new home, adjusting to both 'identity and speed' (McCall [29]). The very speed of the adjustment provides the greatest impact. With these visitors come the potential to significantly impact the culture with new ideas from their adopted country, particularly as there is a parallel reliance on the same relatives for daily subsistence in their home community through remittances. This traveller can go deep into the traditional culture, past any superficial barrier imposed by hosts. These migrants return to 'home' on a remarkably regular basis as the home journey remains a resilient socio-cultural attribute.

The cost of travel has become very competitive with low cost airlines decreasing travel seasonality. However a degree of price insensitivity occurs despite traveller income, largely due to: social motives for travel; a sense of obligation and even fulfilment (Bull [30]). Returning 'home' for a visit is important, maintaining ties, duties and obligations reaffirming the Samoan identity. A study of Samoan residents in Seattle found journeying to Samoa was a defining element of Samoan identity (McGrath [22]). Barker [31] studied Samoan migrants in the US and identified that 25 per cent lived below the level of poverty; comprising the largest immigrant group living in poverty. Yet remittances and travel to Samoa is important for nearly all immigrants (Barker [31], NZ Ministry of Women Report [27]). With low incomes, the cost of the air ticket is a significant part of the total cost of the trip and bringing gifts and money more important than expensive holidays.

Paci [32] suggested that a deeper understanding is required regarding migration, mobility, ethnic differentials and motivation surrounding VFR travel to understand the holiday/obligation incongruities. Yet little further understanding has been gleaned regarding the characteristics of this market segment since Paci's study in 1994.

\section{Impacts}

Only one respondent (of 49 respondents) indicated they did not have an overseas relative visiting them periodically. Furthermore, 94 percent of respondents considered that VFR travellers impacted the Samoan socio-cultural fabric in a myriad of ways, some positive and others negative. Perceived impacts varied across socio-cultural elements and inter related variables indicating the level of complexity in understanding community dynamics. Level of impact is cited by respondents as dependent upon:

- $\quad$ Frequency of visits;

- Commodities and services that hosts must provide; 
- $\quad$ Frequency of provision of these commodities and services;

- $\quad$ The level that VFR travellers participate in community activities.

The VFR traveller did not provide significantly different impacts to the socio-cultural fabric than holiday tourists. The main areas whereby VFR travellers were perceived to impact the socio-cultural fabric more than holiday tourists included: chiefly system; reciprocity; building styles; the family; and emotions of shame, face and respect. Impact was considered positive in many instances, probably enhanced by the importance of this traveller to the economy through remittances. This may also be partly due to the local response, whereby visitors were expected by the hosts to remain involved in cultural activities. Host respondents accorded less concern to VFR travellers impacting the culture than to holiday tourists, despite similar key elements impacted by both visitors.

\subsection{Chiefly system}

The migration of relatives overseas has encouraged greater individualism (UNESCO [23]), which can undermine the traditional dependency underlying the matai system. Through remittances, community members have access to money and other resources, decreasing dependency on family and chiefs, whom had traditionally provided support and decisions. Individuals now have opportunities to live outside the community using personal resources to cater for immediate families, leading to a more individualistic and self reliant lifestyle. Furthermore, remittances are generally sent to parents, siblings and close relatives rather than to a matai who traditionally managed family affairs, strengthening individual power and weakening matai control (UNESCO [23]).

Another issue which has arisen is that some visiting relatives have challenged the authority of the matai and the village fono, in different ways, bringing new ways of thinking and social organising skills. On behalf of their relatives, they challenge the rights of the village to constrain individual rights as stated in the Samoan Constitution (UNESCO [23]).

What this discussion indicates is that the way VFR travellers impact the chiefly system is strongly influenced by money; including providing community individuals access to money resources that they previously had little access to, resulting in less dependency on the chiefly system, offering opportunities that may not have been accessible in the past. This greater financial self reliance is largely augmented through both remittances and visits home. Financial independence can also enable community members to contribute more to their community and towards obligations to their chiefs. To what extent this may occur is unclear as it can impinge on the non-formal economy.

Various scenarios can emerge from these outcomes.

- Ideally the chiefly system can strengthen its leadership and decision making role. This would strengthen the contemporary Samoan culture, based on traditional social ties and elements of social and cultural capital, yet become more responsive to contemporary economic needs. In a spin off this would maintain the cultural product that tourism currently so heavily relies upon. 
- On the other hand change can diminish the role of the chiefly system, whereby the culture will also become more western and individualistic. This can be challenging for the tourism product, as Samoa would then have to compete for tourist dollars with other island destinations which are more competitive in mainstream tourism. This is the scenario occurring to a degree in some communities studied, spurred on by the lack of understanding of the relevance of culture to the tourism product.

\subsection{Reciprocity}

The current research supports the assumption that reciprocity remains strong within the Samoan culture despite the cash economy contributing to a growing imbalance of wealth within the communities. Yet the nature of reciprocity has evolved whereby ceremonial exchange has integrated a monetary value (Young et al [3]) shifting from mutual benefit towards more individual benefit. Consequently the current research has contributed to recognising the importance of maintaining the intrinsic basis of reciprocal exchange process, controlling levels of monetary exchange. This in turn supports a greater equality in communities, based on culture rather than wealth.

This is supported by Putnam [33] who recognised the importance of social networks and rules which dictate how these networks are conducted, involving mutual obligations and sturdy norms of reciprocity. Furthermore, different forms of reciprocity can include: "I will do this for you if you do this for me" and also "a norm of generalized reciprocity: I'll do this for you without expecting anything specific back from you, in the confident expectation that someone else will do something for me down the road" (Putnam [33]). Communities based around the latter type of reciprocity are more effective and efficient than distrustful communities with weak social networks (Putnam [33]).

Within the context of the VFR traveller, the cash economy and consequent social inequalities have made it more difficult to practice this generalised traditional reciprocity. The VFR traveller influences the nature of reciprocity from an intrinsic value to a more extrinsic value based on monetary exchanges. The current research suggested more respondents (42 percent) considered that VFR travellers impacted reciprocity, more so than holiday tourists (35 percent).

Relatives have visited family, bringing gifts for generations and although this continues, there can be some resentment on the part of the host and shame on the part of the guest especially amongst hosts who cannot provide much to guests (Hezel [34]). The VFR traveller must also conform to appropriate community behaviours, whereas those who reside in liberal societies are reluctant to follow traditional ways as rigidly. Moreover, many VFR travellers lead busy working lifestyles, seeking a more relaxed holiday than what is expected of them by hosts. What this suggests is that hosts and guests may have differing ideas of what hospitality and reciprocity means and place 'unreal' expectations on each other. These expectations and the recognition of the associated obligations has led to many VFR travellers ashamed to ask for hospitality from their relatives as they recognize that 'everything costs money these days' (Hezel [34]). 
Consequently VFR travellers who can afford it tend to stay in hotels and guesthouses, offsetting obligations underlying reciprocity. It can also allay feelings of shame on the part of the host, who may not be able to provide a high level of hospitality and with respect to the guest recognizing that they are putting hosts at a disadvantage. This is reflected in considerable numbers budget accommodation available across Samoa, many catering to VFR travellers, enabling them to relax and not conform as rigidly to cultural expectations. In this respect Samoa manages both VFR travellers and cultural preservation within its tourism product, indicating a degree of socio-cultural resilience.

\subsection{Building styles and VFR travellers}

Literature has recognized that many tourists seek to experience a westernized and comfortable view of island cultures (Douglas [35]). This indicates an incongruity between tourists' wealth and understanding local conditions, whereby although tourists want to see different things, they want to experience them from a place of comfort, not from the reality (Urry [36], Muzaini [37], Kaplan [38]). Tourists seek unique cultural attributes, yet also want comfortable and air conditioned accommodation. This supports the assertion that 'tourists and hosts mutually shape the social realities they share' (Hunter [39]). This impacts building styles, although they may have a traditional flavour, they are adapted to meet tourist comfort demands.

How this affects the VFR/host relationship is interesting as it indicates that VFR travellers have changed since migration. For example, as Samoa is very hot, many travellers find it difficult to acclimatise when visiting from a cool place and seek air conditioning, as well as hot showers, which are often unavailable in the communities.

\subsection{Impacts on host families}

VFR travellers affect family differently than holiday tourists. Firstly, they bring gifts of household and personal items to their families as well as money. Secondly, these travellers can provide financial support which can influence community decisions including nominations for specific family members to become a matai. Yet, on the other hand the host also face extra costs as they accompany their relatives to various cultural activities, spending larger amounts of money than normal. This influence on host activities by their guests can encourage them to "act like tourists in their own backyards" (Johns and Gyimothy_[40]). This can put considerable financial and cultural pressure on host families as they feel compelled to undertake activities they cannot afford. A report from the UK indicated that VFR travellers can stimulate additional spending by their hosts, Beioley [41] and Paci [32] suggested, an unseen multiplier effect, whereby additional expenditures are incurred by hosts entertaining guests. It can also place hosts in a difficult position when they must ensure their overseas relatives uphold appropriate and sensitive behaviours to maintain family 'face'. These studies supported the findings of the current research. 


\subsection{Shame face and respect}

Shame, face and respect constitute very different emotions and meanings for Samoans than for mainstream western society. Mesquita [42] strengthens this statement by suggesting that virtually every aspect of emotion is under indigenous cultural influence (such as Samoa) and Western cultures should not be set as the norm of human psychological functioning, measuring other peoples against this norm. These self-conscious emotions may be 'appraised, displayed, and regulated' differently in Westerners and Samoans based around their very different cultural models. When people show respect, their attitude and feelings also arise from their cultural model which recognizes people's dignity, deservingness, acknowledgement, and entitlement (Barreto and Ellemers [43], Heuer et al [44]). Yet while respondents' considered these emotions are impacted by both VFR travellers and holiday tourists, hosts are more willing to endure impacts from relatives as they are 'family' and these relatives also remit.

\section{Links to socio-cultural resilience}

This research offers a glimpse into ways the socio-cultural fabric inherently operates resilience mechanisms to protect its integrity from undesirable external influences, yet embraces more favoured influences. It confirms that VFR travellers to Samoa do impact the socio-cultural fabric in a myriad of ways, some positive and others negative.

Putnam [33] suggested, it is important to strategise how positive social capital consequences can be strengthened and negative consequences minimised. To understand which aspects of social and cultural capital need to be strengthened there is a need to: recognise which elements and inter-relationships are impacted by VFR travel; measure the impact on these elements and inter-relationships; identify which elements and inter-relationships remain strong; recognise and acknowledge where VFR travel contributes to socio-cultural resilience.

Taking from literature, 'resilience' is seen as a useful concept to understand human adaptation (Holling and Goldberg [45], Holling [46], Vayda and McCay [47], Dutra [48]). A key concept of resilience is based on the idea that culture is the force whereby people confront nature and mould it to meet their purpose, constraining behaviours to fit in certain moulds which sustain societies at an ecological and societal equilibrium (Anderson [49], Moran [50]). Dutra [48] suggested it is the lack of awareness of these social and ecological systems which contributes to socio-cultural erosion. Dutra [48] further suggests '... the concept of resilience shifts policies from those that aspire to control change in systems assumed to be stable, towards managing the capacity of socialecological systems to cope with, adapt to, and shape change'. This links the current discussion to that of Putnam [33] regarding strengthening resilience of socio-cultural elements and relationships in communities to strengthen the community health and capabilities. 


\section{Conclusion}

The report has investigated the interrelationships between VFR travellers and hosts previously only assumed and alluded to. More specifically the current research recognized the complexity and multifaceted nature of interrelationships between VFR travel and the socio-cultural fabric. Moreover those socio-cultural systems which have a greater level of resilience can absorb and respond better to shocks and change, having an inherent ability to 'cope with, adapt to, or reorganise' social and economic opportunities without losing an original identity. The information gained through this research has offered a glimpse into critical aspects of the VFR travel product which can offer planners some control over socio-cultural adaptation.

\section{References}

[1] Central Bank of Samoa. Selected Economic Indicators 2007, http://www.cbs.gov.ws/statistics/sei/index.html

[2] Husbands, W., Social Status and Perception of Tourism in Zambia. Annals of Tourism Research, 16, pp. 237-253, 1989.

[3] Young, C. Corsun, D. \& Baloglu, S., A taxonomy of hosts visiting friends and relatives. Annals of Tourism Research, 34 (2). pp. 497-516, 2007.

[4] McKercher, B. Attracting the invisible tourist market: VFR tourism in Albury Wodonga, Australia. in L.C. Harrison and W. Husbands (eds) 'Practicing Responsible Tourism: International Case Studies in Tourism Planning, Policy and Development'. New York: John Wiley, pp. 509-29, 1996.

[5] Belisle, F. \& Hoy, D., The Perceived Impact of Tourism by Residents: A Case Study in Santa Marta, Columbia. Annals of Tourism Research, 7, pp. 83-101, 1980.

[6] Liu, J.C, Sheldon, P. \& T. Var., Resident perceptions of the environmental impact of tourism. Annals of Tourism Research, 14, pp. 17-37, 1987.

[7] Lankford, S. and Howard, D., Developing a Tourism Impact Attitude Scale. Annals of Tourism Research. 21, pp. 121-139, 1994.

[8] Milman, A. \& Pizam, A., Social Impacts of Tourism on Central Florida. Annals of Tourism Research, 15, pp. 191-204, 1988.

[9] Ryan, C. \& Montgomery, D., The Attitude of Bakewell Residents to Tourism and Issues in Community Response Tourism. Tourism Management, 15, pp. 358-369, 1994.

[10] Jackson, R., VFR Tourism: Is it Underestimated? The Journal of Tourism Studies, 14 (1), pp. 17-23, 2003.

[11] Mercer, C., Cultural Capital and Capabilities: Defining and measuring the cultural field. Paper prepared for the Third Global Forum on Human Development: Cultural identity, democracy and global equity. Paris, 2005.

[12] Saunders, P., The Social Foundations of a Free Society. The Centre for Independent Studies, Sydney. 2001.

[13] Black, A. \& Hughes, V., The identification and analysis of indicators of community strength and outcomes, FaCS Occasional Paper. No 3, 2001. 
[14] Australian Bureau of Statistics. Measuring Social Capital: An Australian Framework and Indicators. Commonwealth of Australia. 2004, http://www.abs.gov.au

[15] Bourdieu, P., The Forms of Capital, in Richardson (Ed), Handbook of theory and research for the sociology of education. Greenwood Press, pp. 241-258, New York, 1986.

[16] Lehto, X. Morrison, A. \& O’Leary, J., Does the Visiting Friends and Relatives' Typology Make a Difference? A Study of the International VFR Market to the United States. Journal of Travel Research, 40 (2), pp. 201212, 2001.

[17] Moscardo, G. Pearce, P. Morrison, A. Green, D. \& O'Leary, J.T., Developing a typology for understanding visiting friends and relatives markets'. Journal of Travel Research, 38 (3), pp. 251-59, 2000.

[18] Lee, G. Morrison, A. Lheto, X. Webb, J. \& Reid, R., VFR: Is it really marginal? A financial consideration of French overseas travellers. Journal of Vacation Marketing, 11 (4), pp. 340-356, 2005.

[19] Duval, T., When Hosts become Guests: Return Visits and Diasporic Identities in a Commonwealth Eastern Caribbean Community. Current Issues in Tourism, 6 (4), pp. 267-271, 2003.

[20] Seaton, A. \& Palmer, C., Understanding VFR tourism behaviour: The first five years of the United Kingdom tourism survey. Tourism Management, 18 (6), pp. 345-55, 1997.

[21] Backer, E., VFR Travellers - Visiting the destination or visiting the hosts? Asian Journal of Tourism and Hospitality Research, 2 (2), pp. 60-70, 2008.

[22] McGrath, B., Seattle Fa'a Samoa. The Contemporary Pacific, 14 (2), pp. 307-340, 2002.

[23] UNESCO, Exploring Global Movement Using Local Realities. Department of Sociology, University of Auckland. New Zealand, 2000.

[24] Springer, B., Caribbean: Courting the Diaspora. Latin American News Agency. 2008. http://www.trulycaribbean.net

[25] Shankman, P. The Samoan Exodus. Contemporary Pacific Societies in Development and Change. Lockwood, V. Harding, T. and Wallace, B. (Eds) Englewood Cliffs. NJ, Prentice Hall, pp. 156-170, 1993.

[26] Samoan VFR Traveller, per communication, 2005.

[27] New Zealand Ministry of Women Report. Pacific Women's Economic WellBeing Project Summary Report. Ministry of Women's Affairs. 2006. http://www.mwa.govt.nz

[28] Joint Samoa Program Strategy (2006-2010) Government of Samoa, Government of Australia, Government of New Zealand. November 2006.

[29] McCall, G., Nissology: The study of islands. Journal of the Pacific Society, pp. 1-14, October 1994.

[30] Bull, A., The Economics of Travel and Tourism. Pitman, Sydney, 1991.

[31] Barker, J., Pacific Island Migrants in the United States: Some Implications for Aging Services. Journal of Cross-Cultural Gerontology, 6(2), pp. 173$192,1991$. 
[32] Paci, E., The major international VFR markets. EIU Travel and Tourism Analyst, 6, pp. 36-50, 1994.

[33] Putnam, R., Bowling Alone: The Collapse and Revival of American Community. New York, Simon and Schuster, 2000.

[34] Hezel, F., The Cruel Dilemma: Money Economies in the Pacific. Journal of Pacific Theology, Series II, (8), pp. 11-22, 1992.

[35] Douglas, N., They Came for Savages: 100 Years of Tourism in Melanesia. Southern Cross University Press, Alstonville, Australia, 1997.

[36] Urry, J., The Tourist Gaze: Leisure and Travel in Contemporary Societies. London, Sage Publications, 1990.

[37] Muzaini, H., Backpacking South East Asia: Strategies of 'Looking Local. Annals of Tourism Research, 33 (1), pp. 144-161, Pergamon, 2005.

[38] Kaplan, C., Questions of Travel: Postmodern Discourses of Displacement. London, Duke University Press, 1996.

[39] Hunter, W., Trust between Culture: The Tourist. Current Issues in Tourism. 4 (1). Department of Leisure and Sport Management, and Foreign Languages. Tajen Institute of Technology, Republic of China. 2001.

[40] Johns, N. \& Gyimothy, S., Market Segmentation and the Prediction of Tourist Behavior: The Case of Bornholm, Denmark, Journal of Travel Research, 40 (3), pp. 316-327, 2002.

[41] Beioley, S., Four weddings, a funeral and a holiday: The visiting friends and relatives market. Insights, 8, 1997.

[42] Mesquita, B., Emotions as dynamic cultural phenomena, in Davidson, R. \& Goldsmith, H. \& K. R. Scherer (eds.) The handbook of the affective sciences. Oxford University Press, New York, pp. 871-890, 2003.

[43] Barreto, M. \& Ellemers, N., The impact of respect vs. neglect of selfidentities on identification and group loyalty. Personal Social. Psychology Bulletin. In press, 2001.

[44] Heuer, L. Blumenthal, E. Douglas, A. \& Weinblatt, T., A deservingness approach to respect as a relationally based fairness judgment. Personality and Social Psychology Bulletin, 25 (10), pp. 1279-1292, 1999.

[45] Holling, C. \& Goldberg, M., Ecology and Planning. Journal of the American Institute of Planners. 37, pp. 221-230, 1971.

[46] Holling, C., Resilience and stability of ecological systems. Annual Review of Ecology and Systematics, 4, pp. 1-23, 1973.

[47] Vayda, A.P. \& McCay, B.J., New directions in ecology and ecological Anthropology. Annual Review of Anthropology, 4, pp. 293-306, 1975.

[48] Dutra, L., Sustainability and Resilience. Trans-disciplinary Journeys. PhD candidate, Centre for Ecological Economics and Water Policy Research. University of New England, Australia, 2006.

[49] Anderson, W., Caribbean Immigrants: A Socio-demographic Profile. Toronto: Canadian Scholars, 1993.

[50] Moran, E., Human Adaptability: An Introduction to Ecological Anthropology. Boulder, Colorado, Westview Press, 1979. 